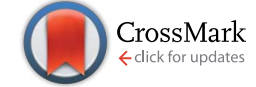

Cite this: RSC Adv., 2017, 7, 6059

\title{
Modular sub-monomeric cell-penetrating guanidine-rich peptoids - synthesis, assembly and biological evaluation $\uparrow$
}

\author{
Etienne Marouseau, ${ }^{a}$ Albane Neckebroeck, ${ }^{a}$ Heidi Larkin, ${ }^{a}$ Antoine Le Roux, ${ }^{a}$ \\ Leonid Volkov, ${ }^{\mathrm{b}}$ Christine L. Lavoie ${ }^{\mathrm{a}}$ and Éric Marsault ${ }^{\star a}$
}

Received 7th December 2016 Accepted 8th January 2017

DOI: 10.1039/c6ra27898a

www.rsc.org/advances

\begin{abstract}
Guanidinium-rich transporters are promising agents to deliver a wide range of molecules through cell membranes. This article reports the synthesis of a modular, conformationally restricted guanidinium display scaffold, designed with the goal to study the impact of conformational restrictions on the resulting properties of the transporters and ultimately probe the anionic chemical space of the cellular membrane. The scaffold was assembled on solid phase as a peptoid, and its subsequent biological evaluation showed very good cellular penetration and low cytotoxicity.
\end{abstract}

\section{Introduction}

A wide range of drug discovery targets are intracellular, such as protein-protein interactions, which makes them difficult to reach. ${ }^{1}$ On the other hand, peptides, ribonucleic acids (RNAs), and more broadly high molecular weight or highly polar molecules, often represent promising leads in vitro for intracellular targets, ${ }^{2}$ yet fail to reach efficacy in cells or in vivo for their inability to cross cell membranes. ${ }^{3}$ There is thus a need for cellular penetration agents for these two chemical spaces to meet.

The discovery of the protein transduction domain of Antennapedia homeodomain and the transactivated transcription (Tat) protein of HIV-1 changed this paradigm, ${ }^{4,5}$ demonstrating that some large peptides can cross cell membranes. From these pioneering works and based on the fundamentals of these observations, cell-penetrating peptides (CPPs) and CPPlike transporters have been further developed and diversified. ${ }^{6}$ Promising proofs of concepts were made, demonstrating the feasibility to deliver otherwise impermeable cargoes to various cell types and tissues, including the brain, using such transporters. $^{7-9}$ CPPs were originally classified in three categories: cationic, amphipathic and lipophilic. ${ }^{\mathbf{1 0 , 1 1}}$

Amongst cationic CPPs, the guanidinium-rich transporters (GRTs) emerged after the observation that polylysines and polyarginines are sufficient and efficient peptides to carry cargos

${ }^{a}$ Institut de Pharmacologie de Sherbrooke, Department of Pharmacology and Physiology, Université de Sherbrooke, 3001, $12^{e}$ Avenue Nord, J1H 5N4, Sherbrooke, QC, Canada.E-mail: Eric.Marsault@usherbrooke.ca

${ }^{b}$ Biophotonics Core Facility, Centre de Recherche du Centre Hospitalier de l'Université de Sherbrooke, 3001, $12^{e}$ Avenue Nord, J1H 5N4, Sherbrooke, QC, Canada

$\dagger$ Electronic supplementary information (ESI) available. See DOI: 10.1039/c6ra27898a inside the cells, and that peptidomimetic analogs, owing to their higher stability, entered cells more readily. ${ }^{12,13}$ Several research groups have subsequently studied GRTs featuring various backbones. ${ }^{13-18}$

Additionally, it has also been shown that the interaction between sulfated (anionic) glycosaminoglycans (GAGs) and GRTs was critical for cellular entry. ${ }^{\mathbf{1 9 , 2 0}}$ However, how precisely these interactions allow cationic CPPs to enter cells is still a matter of debate and several parameters ${ }^{21,22}$ and mechanisms ${ }^{23,24}$ have been proposed and studied. The lack of a toolset to interrogate the cellular membrane chemical space, however, limits this exploration. ${ }^{25}$ In order to better understand this poorly characterized chemical space, we and others reported the use of macrocyclisation as a way to study the impact of GRT conformational restrictions on cellular permeation. ${ }^{\mathbf{2 6 - 3 0}}$

In the present study, we designed novel peptoidic GRTs bearing modular scaffolds, assembled via a sub-monomer approach, to display a conformationally restricted pattern of 2-3 guanidines per sub-monomer. This modular design enables structural variations to sample distances between guanidine moieties, with the goal to explore potential interactions with the negatively charged groups displayed on GAGs. ${ }^{14,31}$ In other words, this design provides a diversifiable cationic chemical space as an exploratory tool to better understand the anionic chemical space of the cellular membrane.

\section{Results and discussion}

Our first objective was to develop a modular synthesis (Fig. 1), hinging around protected sub-monomers S1 assembled in solution, assembly of multimers followed by solid phase guanidinylation. This general strategy is expected to enable modifications to the peptoid sequence and the introduction of additional scaffolds. Thus, Rink amide resin was chosen for 


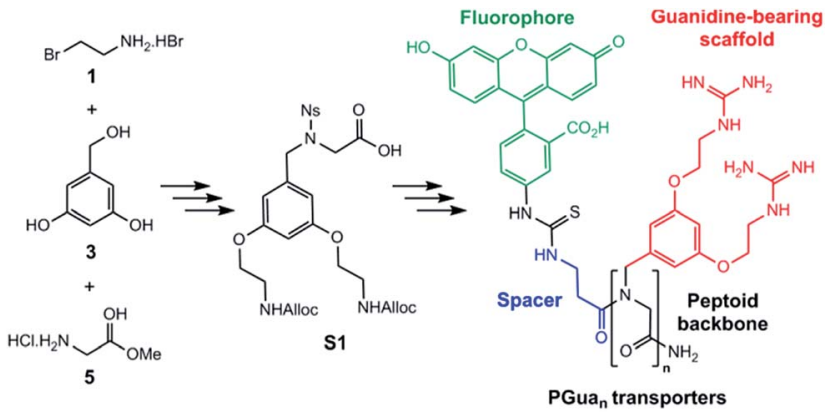

Fig. 1 Synthetic route for PGua ${ }_{n}$ transporters.

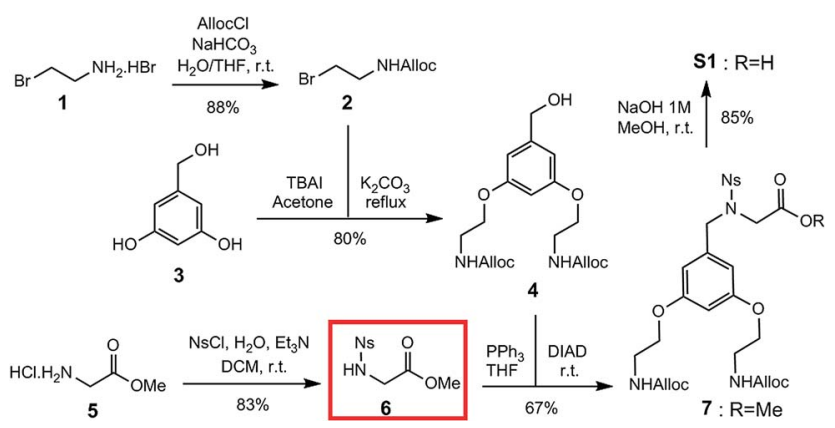

Scheme 1 Solution synthesis of sub-monomer S1.

solid phase synthesis and a $\beta$-alanine spacer between the GRT and the cargo completes the construction. ${ }^{32}$ Fluorescein (FL) was chosen as the first cargo to assess transporter permeability by flux cytometry.

Construction of building block S1 (Scheme 1) started with Alloc protection of 2-bromoethylamine hydrobromide $\mathbf{1}$ in excellent yield to provide 2. Displacement of the bromide of 2 with the phenol groups of 3,5-dihydroxybenzyl alcohol 3 yielded dialkylated intermediate 4 efficiently. Meanwhile, activation of the amine of glycine methyl ester hydrochloride 5 with a 2nitrobenzene sulfonyl (nosyl) group produced intermediate $\mathbf{6}$, isolated by precipitation in excellent yield. Intermediates $\mathbf{4}$ and 6 were then combined using the Fukuyama-Mitsunobu reaction $^{33}$ to obtain intermediate 7 in good yield, which was hydrolyzed in excellent yield to $\mathbf{S 1}$ for an overall yield of $40 \%$.

The next step was to build the corresponding GRT $\left(\mathbf{P G u a}_{n}\right.$, Fig. 2), which was accomplished using submonomer assembly. In order to assess the respective role of backbone and guanidine on properties, the corresponding benzyl and aminated analogues ( $\mathbf{P B n}_{n}$ and $\mathbf{P A m} \mathbf{m}_{n}$, respectively, Fig. 2) were built as controls, as well as the corresponding polyarginines ( $\mathbf{R}_{n}$, Fig. 2). Accordingly, dimers to hexamers were synthesized to assess the impact of guanidine number on permeability.

The first focus was to optimize conditions to obtain aminated and guanidinylated compounds (Scheme 2). A nosylamide alkylation strategy was applied by sequential addition of $\mathbf{S 1}$ followed by nosyl deprotection. The coupling step with hexafluorophosphate azabenzotriazole tetramethyluronium (HATU) and DIPEA to obtain $\mathbf{9}$ worked best with 3 eq. of $\mathbf{S 1}$ and

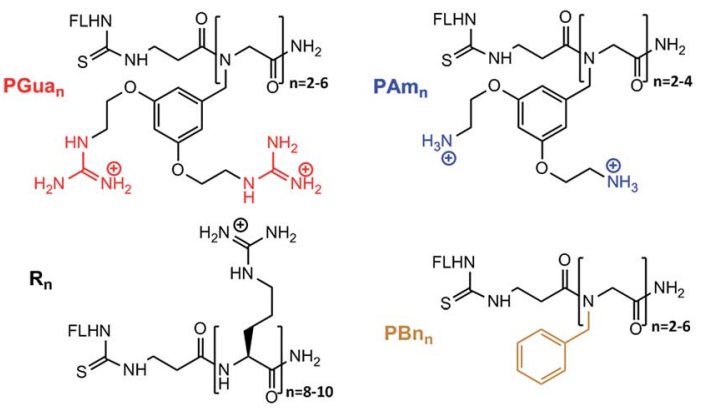

Fig. 2 Structures of the transporters.

was performed overnight to get 10. Nosyl group deprotection was performed using mercaptoethanol and DBU. ${ }^{34}$

After assembling the desired number of submonomers, intermediate $\mathbf{1 1}$ was obtained, and $\beta$-alanine was coupled to obtain intermediate 12. Among several conditions to deprotect the allyl group with palladium(0) tetrakis triphenylphosphine (phenylsilane, ${ }^{35}$ dimedone, $\mathrm{HCl} /$ morpholine and dimethylbarbituric acid (DMBA)), ${ }^{36}$ DMBA gave the best results to generate polyamine 13 . The latter was then guanidinylated with Goodman's reagent (1,3-Di-Boc-2-(trifluoromethylsulfonyl) guanidine) successfully to deliver intermediate $14 .^{15,37}$ Deprotection of the Fmoc protecting group followed by addition of fluorescein isothiocyanate (FITC) yielded intermediate 15.

A mixture of TFA/water/triisopropylsilane (TIPS) simultaneously cleaved the peptoid and deprotected Boc groups to give PGua $_{n}$.

For aminated analogs, the order of steps was changed, starting from 12, to conjugate fluorescein first. Deprotection of the Alloc groups worked well here too, and cleavage from the resin gave $\mathbf{P A m}_{n}$ transporters. Increasing the size of $\mathbf{P G u a}_{n}$ or $\mathbf{P A m}_{n}$ was uneventful. Overall yield remained close to $10 \%$ after purification. To assess potential contributions of the aromatic backbone on cellular penetration, FL- $\beta$ Ala- $(\mathrm{NPhe})_{n}-\mathrm{NH}_{2}\left(\mathbf{P B n}_{n}\right)$ were chosen as non-functionalised controls. The bromoacetic acid strategy was applied to these syntheses (Scheme 2), ${ }^{38}$ in overall good yields (up to 55\%) after purification. Finally, control polyarginine transporters $\left(\mathbf{R}_{\boldsymbol{n}}\right)$ were synthesized using standard Fmoc chemistry with Fmoc-Arg(Pbf)-OH.

As a primary biological assay, to validate which compounds qualified for further analyses, permeation was evaluated with flow cytometry in HeLa cells. ${ }^{39}$ Uptake was measured by the displacement of the mean cell fluorescence after incubation with $5 \mu \mathrm{M}$ fluorescein-labelled compounds in culture medium compared to a blank. To ensure extracellular fluorescence quenching, cells were incubated with trypsin before analysis, ${ }^{19,40}$ and a buffer containing trypan blue was added (see ESI $\dagger$ ). ${ }^{41}$ The first results (Fig. 3) validated several hypotheses: (1) non-functionalized control analogs (Fig. 3A) showed no significant difference compared to blank, proving backbone is not responsible for uptake; (2) aminated analogs (Fig. 3B) did not show any significant cellular penetration with up to 8 amine moieties; (3) guanidinylated compounds (Fig. 3C) start entering cells with 6 guanidines and showed a maximal uptake of $80 \%$ of 


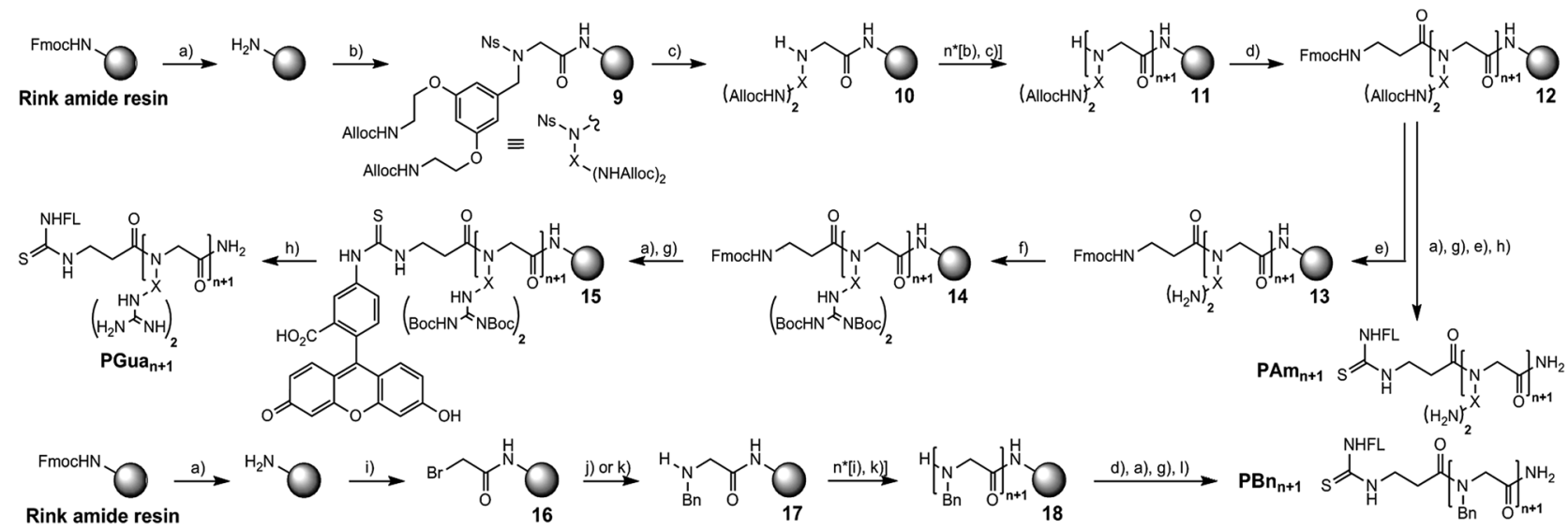

Scheme 2 Solid phase synthetic routes of PGua, $\mathrm{PAm}_{n}$ and PBn $\mathrm{P}_{n}$. Reagents and conditions: (a) 20\% pip in DMF, rt, 20 min; (b) 3 eq. S1, 3 eq. HATU, 6 eq. DIPEA, DMF, rt, o/n; (c) 10 eq. mercaptoethanol, 5 eq. DBU, DMF, rt, $2 \times 30$ min; (d) 5 eq. Fmoc- $\beta A$ la-OH, 5 eq. HATU, 6 eq. DIPEA, DMF, rt, $2 \times 1$ h; (e) 0.5 eq./Alloc Pd(PPh $)_{4}, 2$ eq./Alloc DMBA, DCM, rt, 2 h; (f) 2 eq./amine Goodman's reagent, 2 eq./amine DIPEA, DCM, rt, 4 h; (g) 2 eq. FITC, 4 eq. DIPEA, DCM/Pyr (7 : 3), rt, 30 min; (h) TFA/TIPS/water (95: $2.5: 2.5)$, rt, 2 h; (i) 5 eq. bromoacetic acid, 2.5 eq. DIC, DCM, rt, 15 min; (j) 2 eq. benzylamine, 6 eq. DIPEA, DMF, rt, o/n; (k) 20 eq. benzylamine, DMF, rt, 1 h; (l) TFA, rt, 1 h.

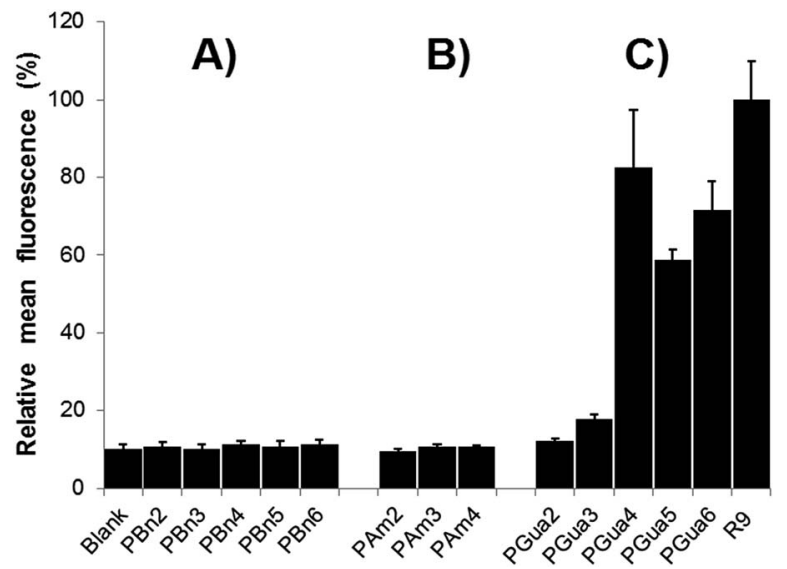

Fig. 3 Cellular penetration of (A) backbone-only analogs; (B) aminated analogs; (C) guanidinylated analogs and nonaarginine in HeLa cells as determined by flow cytometry. Standard deviation was calculated according to the number of experiments; $\mathrm{PBn}_{4} n=15$; blank $n=12$; $\mathrm{PBn}_{2,5,6}, \mathrm{PGua}_{5,6}$ and $\mathrm{R}_{9} n=8 ; \mathrm{PBn}_{3}$ and $\mathrm{PGua}_{4} n=7 ; \mathrm{PAm}_{2,3,4}$ and $\mathrm{PGua}_{2,3} n=6$. Mean fluorescence was normalized with respect to control $\mathrm{R}_{\mathbf{9}}$

the reference $\mathbf{R}_{\mathbf{9}}$ for 8 guanidines, consistent with previous literature. ${ }^{42}$

GAGs have been shown to be key for cellular selectivity. ${ }^{\mathbf{1 4 , 4 3 , 4 4}}$ and a potentially important avenue to cancer-targeted delivery. ${ }^{45}$ Hence, the second experiment was intended to assess the dependence of cellular uptake upon GAGs. Thus, GAG-depleted Chinese hamster ovarian (CHO) cells (pgsA-745), ${ }^{\mathbf{4 6}}$ and wild type cells (CHO-K1), were incubated in the same conditions as described for HeLa cells, and flow cytometry analysis was performed (Fig. 4). In CHO-K1 cells, the uptake of PGua compounds was found to be significantly lower compared to polyarginines, with diminution ranging from $28 \%\left(\mathbf{P G u a}_{\mathbf{4}}\right)$ to $58 \%\left(\right.$ PGua $\left._{6}\right)$ compared to HeLa cells. This suggests that, as opposed to Hela cells, CHO-K1 cells discriminate polyarginines

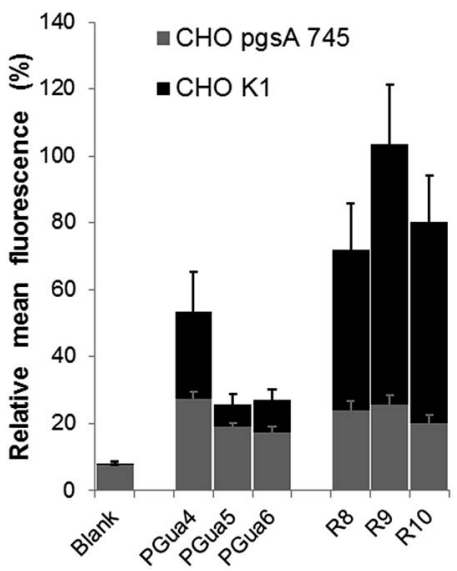

Fig. 4 Cellular penetration of guanidinylated analogs and polyarginines in $\mathrm{CHO}-\mathrm{K} 1$ (black) and $\mathrm{CHO}-$ pgsA-745 (grey) as determined by flow cytometry. Each value represents an average of 8 experiments, with the standard deviation. Mean fluorescence was normalized with respect to control $\mathbf{R}_{\mathbf{9}}$.

compared to this new GRT scaffold. This also suggests that a structure-permeability relationship is achievable with the various cell lines, similarly to our reports with macrocyclic GRTs. $^{29}$

In CHO-pgsA-745 cells, the uptake of guanidinylated compounds $\left(\mathbf{P G u a}_{\boldsymbol{n}}\right)$ and polyarginines were both abrogated. Interestingly, the remaining levels of uptake compared to $\mathrm{CHO}$ $\mathrm{K} 1$ cells, irrespective of compounds, remained around $20 \%$ (Fig. 4) with very low standard deviation, independently of their structures or number of guanidines. This suggests the presence of a dual uptake mechanism (one dependent on GAGs and modular, the other independent of GAGs and non-modular).

Finally, cytotoxicity was assessed for a series of analogous compounds $\left(\mathbf{P B n}_{\mathbf{4}}, \mathbf{P A m}_{\mathbf{4}}, \mathbf{P G u a}_{\mathbf{4}}\right.$ and $\left.\mathbf{R}_{\mathbf{8}}\right)$ using the lactate dehydrogenase (LDH) assay. ${ }^{47}$ 


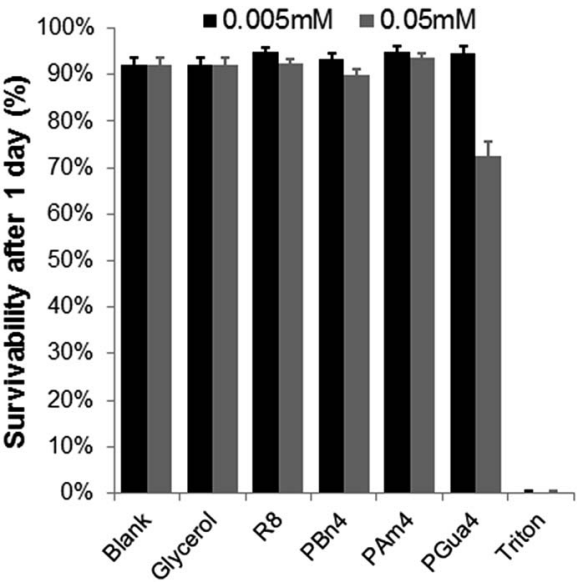

Fig. 5 Cellular toxicity of $\mathrm{PGua}_{4}$ and its analogs in HeLa cells. Each value represents an average of 6 experiments, with its standard deviation shown. Triton was used as a negative control.

As shown in Fig. 5, no significant cytotoxicity was observed for the compounds tested, except for $\mathbf{P G u a} 4$, which induced $25 \%$ mortality at $50 \mu \mathrm{M}$ concentration only.

\section{Conclusion}

A new type of sub-monomer was created to synthesize GRTs based on a peptoid backbone. Solid phase synthesis worked well and is applicable to subsequent backbone diversification. Biological results confirm that this scaffold is conducive of good cellular uptake. The best compound in this class so far proved to be $\mathbf{P G u a}_{4}$, bearing 8 guanidine groups, which was superior to similar scaffolds bearing 10 or 12 guanidines. Flow cytometry suggests the potential presence of dual mechanisms of uptake of the compounds in CHO cells. Finally, cell survival assay showed promising results with a low cytotoxicity for $\mathbf{P G u a}_{4}$. This demonstrates that the proposed methodology is promising and that further investigations could identify new GRT structures to support the development of structure-cellular penetration relationship. This toolset provides the first step of a broader project aimed at providing a broad cationic chemical space as a complement to interrogate the anionic chemical space defined by the cell membrane.

\section{Acknowledgements}

We would like to thank the Natural Sciences and Engineering Research Council of Canada and the Canadian Foundation for Innovation. The FRQNT-funded PROTEO Network and the Institut de Pharmacologie de Sherbrooke are acknowledged for graduate scholarship to E. Marouseau. Pr. Steve Bourgault (Université du Québec A Montréal, QC, Canada) is gratefully acknowledged for providing CHO-K1 and CHO-pgsA-745 cell lines.

\section{Notes and references}

1 S. Mitragotri, P. A. Burke and R. Langer, Nat. Rev. Drug Discovery, 2014, 13, 655-672.
2 C. Corbi-Verge and P. M. Kim, Cell Commun. Signaling, 2016, 14, 1-12.

3 G. L. Verdine and L. D. Walensky, Clin. Cancer Res., 2007, 13, 7264-7270.

4 D. Derossi, A. H. Joliot, G. Chassaing and A. Prochiantz, J. Biol. Chem., 1994, 269, 10444-10450.

5 E. Vivès, P. Brodin and B. Lebleu, J. Biol. Chem., 1997, 272, 16010-16017.

6 S. Stalmans, E. Wynendaele, N. Bracke, B. Gevaert, M. D'Hondt, K. Peremans, C. Burvenich and B. De Spiegeleer, PLoS One, 2013, 8, e71752.

7 M. Pooga, U. Soomets, M. Hällbrink, a. Valkna, K. Saar, K. Rezaei, U. Kahl, J. X. Hao, X. J. Xu, Z. Wiesenfeld-Hallin, T. Hökfelt, T. Bartfai and U. Langel, Nat. Biotechnol., 1998, 16, 857-861.

8 A. Srimanee, J. Regberg and Ü. Langel, in Cell-Penetrating Peptides: Methods and Protocols, ed. Ü. Langel, Springer New York, New York, NY, 2nd edn, 2015, pp. 349-356.

9 J. E. Dixon, G. Osman, G. E. Morris, H. Markides, M. Rotherham, Z. Bayoussef, A. J. El Haj, C. Denning and K. M. Shakesheff, Proc. Natl. Acad. Sci., 2016, 113, E291-E299.

10 R. Fischer, M. Fotin-Mleczek, H. Hufnagel and R. Brock, ChemBioChem, 2005, 6, 2126-2142.

11 K. Kurrikoff, M. Gestin and Ü. Langel, Expert Opin. Drug Delivery, 2016, 13, 373-387.

12 P. A. Wender, D. J. Mitchell, K. Pattabiraman, E. T. Pelkey, L. Steinman and J. B. Rothbard, Proc. Natl. Acad. Sci. U. S. A., 2000, 97, 13003-13008.

13 W. Huang, J. Seo, J. S. Lin and A. E. Barron, Mol. Biosyst., 2012, 8, 2626-2628.

14 L. Elson-Schwab, O. B. Garner, M. Schuksz, B. E. Crawford, J. D. Esko and Y. Tor, J. Biol. Chem., 2007, 282, 13585-13591.

15 T. Schröder, N. Niemeier, S. Afonin, A. S. Ulrich, H. F. Krug and S. Bräse, J. Med. Chem., 2008, 51, 376-379.

16 E. G. Stanzl, B. M. Trantow, J. R. Vargas and P. A. Wender, Acc. Chem. Res., 2013, 46, 2944-2954.

17 Y. Demizu, M. Oba, K. Okitsu, H. Yamashita, T. Misawa, M. Tanaka, M. Kurihara and S. H. Gellman, Org. Biomol. Chem., 2015, 13, 5617-5620.

18 M. Nepal, S. Thangamani, M. N. Seleem and J. Chmielewski, Org. Biomol. Chem., 2015, 13, 5930-5936.

19 J. P. Richard, K. Melikov, H. Brooks, P. Prevot, B. Lebleu and L. V. Chernomordik, J. Biol. Chem., 2005, 280, 15300-15306.

20 L. E. Prevette, N. C. Benish, A. R. Schoenecker and K. J. Braden, Biophys. Chem., 2015, 207, 40-50.

21 J. B. Rothbard, T. C. Jessop and P. A. Wender, Adv. Drug Delivery Rev., 2005, 57, 495-504.

22 R. Wallbrecher, W. P. R. Verdurmen, S. Schmidt, P. H. BoveeGeurts, F. Broecker, A. Reinhardt, T. H. Van Kuppevelt, P. H. Seeberger and R. Brock, Cell. Mol. Life Sci., 2014, 71, 2717-2729.

23 P. A. Wender, W. C. Galliher, E. A. Goun, L. R. Jones and T. H. Pillow, Adv. Drug Delivery Rev., 2008, 60, 452-472.

24 A. Tchoumi Neree, P. T. Nguyen and S. Bourgault, Int. J. Mol. Sci., 2015, 16, 27391-27400.

25 M. E. Favretto, R. Wallbrecher, S. Schmidt, R. Van De Putte and R. Brock, J. Controlled Release, 2014, 180, 81-90. 
26 D. Oh, S. A. Darwish, A. N. Shirazi, R. K. Tiwari and K. Parang, ChemMedChem, 2014, 92618, 2449-2453.

27 R. Wallbrecher, L. Depré, W. P. R. Verdurmen, P. H. BovéeGeurts, R. H. Van Duinkerken, M. J. Zekveld, P. Timmerman and R. Brock, Bioconjugate Chem., 2014, 25, 955-964.

28 N. Nischan, H. D. Herce, F. Natale, N. Bohlke, N. Budisa, M. C. Cardoso and C. P. R. Hackenberger, Angew. Chem., Int. Ed., 2015, 54, 1950-1953.

29 H. Traboulsi, H. Larkin, M. A. Bonin, L. Volkov, C. L. Lavoie and É. Marsault, Bioconjugate Chem., 2015, 26, 405-411.

30 Z. Qian, A. Martyna, R. L. Hard, J. Wang, G. Appiah-Kubi, C. Coss, M. A. Phelps, J. S. Rossman and D. Pei, Biochemistry, 2016, 55, 2601-2612.

31 M. Okuyama, H. Laman, S. R. Kingsbury, C. Visintin, E. Leo, K. L. Eward, K. Stoeber, C. Boshoff, G. H. Williams and D. L. Selwood, Nat. Methods, 2007, 4, 153-159.

32 M. Jullian, A. Hernandez, A. Maurras, K. Puget, M. Amblard, J. Martinez and G. Subra, Tetrahedron Lett., 2009, 50, 260263.

33 T. Fukuyama, C. K. Jow and M. Cheung, Tetrahedron Lett., 1995, 36, 6373-6374.

34 E. Biron, J. Chatterjee and H. Kessler, J. Pept. Sci., 2006, 12, 213-219.

35 J. M. Palomo, RSC Adv., 2014, 4, 32658-32672.
36 D. Fernández-Forner, G. Casals, E. Navarro, H. Ryder and F. Albericio, Tetrahedron Lett., 2001, 42, 4471-4474.

37 K. Feichtinger, H. L. Sings, T. J. Baker, K. Matthews and M. Goodman, J. Org. Chem., 1998, 63, 8432-8439.

38 R. N. Zuckermann, J. M. Kerr, S. B. H. Kent and W. H. Moos, J. Am. Chem. Soc., 1992, 114, 10646-10647.

39 A. Gräslund, F. Madani, S. Lindberg, Ü. Langel and S. Futaki, J. Biophys., 2011, 2011, 414729.

40 J. P. Richard, K. Melikov, E. Vives, C. Ramos, B. Verbeure, M. J. Gait, L. V. Chernomordik and B. Lebleu, J. Biol. Chem., 2003, 278, 585-590.

41 J. Hed, G. Hallden, S. G. O. Johansson and P. Larsson, J. Immunol. Methods, 1987, 101, 119-125.

42 H. Silva, F. Frézard, E. J. Peterson, P. Kabolizadeh, J. J. Ryan and N. P. Farrell, Mol. Pharmacol., 2012, 9, 1795-1802.

43 K. J. Lim, B. H. Sung, J. R. Shin, Y. W. Lee, D. J. Kim, K. S. Yang and S. C. Kim, PLoS One, 2013, 8, e66084.

44 S. Stalmans, N. Bracke, E. Wynendaele, B. Gevaert, K. Peremans, C. Burvenich, I. Polis and B. De Spiegeleer, PLoS One, 2015, 10, e0139652.

45 I. Geisler and J. Chmielewski, Chem. Biol. Drug Des., 2009, 73, 39-45.

46 X. Bai, G. Wei, A. Sinha and J. D. Esko, J. Biol. Chem., 1999, 274, 13017-13024.

47 E. Amador, L. E. Dorfman and W. E. Wacker, Clin. Chem., 1963, 12, 391-399. 